\title{
Study on the Movement Law of Overburden Strata During Mining Strip Pillar with Paste
}

\author{
Guo Weijia ,Li Yangyang,Zhang Baoliang,Wang hailong,Sun xizhen \\ State Key Laboratory of Mining Disaster Prevention and Control Co-founded by \\ Shandong Province and the Ministry of Science and Technology,Shandong University of \\ Science and Technology, Qingdao 266590, China
}

\begin{abstract}
The movement law of overburden strata in backfill mining face was studied, by the method of similar material simulation, on the background of the paste filling mining in Daizhuang Coal Mine, and in consideration of change of filling body strength with time. The results showed that the immediate roof by caving method can be converted to basic roof by full mining and full backfill, and they can keep force transfer in advance direction. The roof structure of "coal pillar-coal wall" became the roof structure of "coal pillar-filling body-coal wall" in the process of fill mining, which can control mining subsidence effectively.
\end{abstract}

Keywords: paste filling mining, similar material simulation, filling rate, strip pillar, overburden strata movement.

\section{Introduction}

The problem of mine occupied by village is becoming more and more outstanding because of the development of our country, which restricted the sustainable development of most mine enterprises. Coal reserve under building, railway, water body of our country can research 13790million tons, and about 69 percent of them were occupied by building.According to date from Shandong province, coal reserve under building is 4400 million tons, which account for 53 percent of recoverable reserves. There are over 3600 villages in Jining district, and have to move 564 villages before $2012^{[1]}$.

The ways of controlling overburden movement, reducing surface subsidence include: strip mining ${ }^{[2]}$, grouting separated strata zone in overburden ${ }^{[3]}$, backfill mining ${ }^{[4]}$ and so on. Strip mining 
can control surface subsidence effectively, but waste resources seriously. Grouting separated strata zone in overburden can't meet a higher protection requirements of buildings. Backfill mining can not only reduce surface subsidence and resources waste, but also can protect environment very well. Study on the movement law of overburden strata during mining strip pillar with filling-body and compression deformation of backfill body is significant in making backfilling schemes, controlling surface subsidence, protecting buildings and environment of mining area..

\section{Test model of similar material simulation}

\subsection{Engineering background}

2351 paste backfill mining face mines strip coal pillar of 2300 mining area of Daizhuang Coal Mine, which lies in northwestward of west belt down hill of -410 meters level. There is 5.0 meters pillar between 2351 working face and the track transportation tunnel of 2302 working face in the northeastern side. There is 5.0 meters pillar between 2351 working face and the track transportation tunnel of 2303 working face in the southwestern side. There is 30.0 meters pillar between open-off cut of 2351 working face and open-off cut of 2352 working face. The distance between 2351 working face and -485 meters subsidiary level is 150 meters. Concrete position of 2351 paste filling working face is showed in Fig.1.

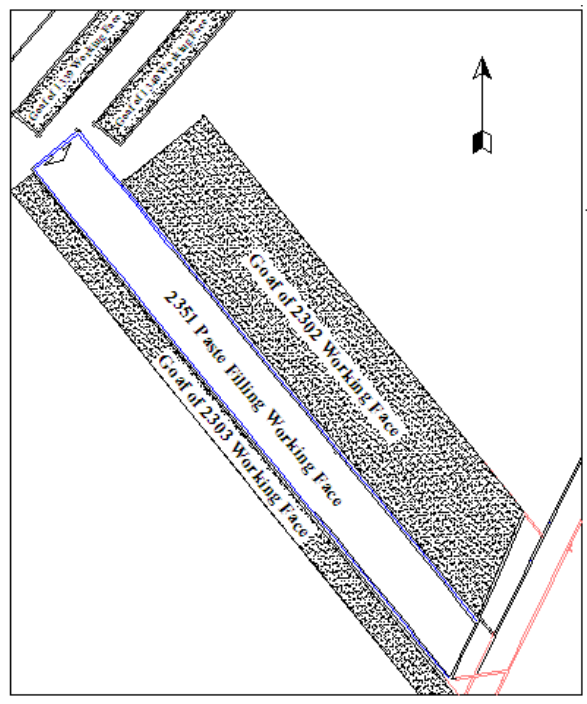

Fig.1: Relation between 2351 working face and gob around .

Length of 2351 paste backfill mining face is 103 meters, and its strike length is 1071 meters. Coal seam thickness is from 1.08 to 3.10 meters, average is 2.65 meters. Angle of coal seam range from 3 to 13 degrees, average is 5 degrees.

Mining method of 2351 paste backfill mining face is full mining and full backfill. With the increase of roof stability and improvement of operation proficiency, filling step increased to 3.5 meters from 2.0 meters.

\subsection{Model laying}

According to dimensional principle of similar material proportion and test results of similar material proportion, considered model size, proportional 
similarity were determined as following: geometric similarity coefficient equals $100\left(C_{l}=100\right)$. Similarity coefficient of bulk density equals $1.5\left(C_{\gamma}=1.5\right)$. Similarity coefficient of stress equals 150( $\left.C_{\sigma}=C_{\gamma} \cdot C_{l}=150\right)$ Similarity coefficient of time equals $10\left(C_{t}=\sqrt{C_{L}}=10\right)$. In order to meet the demand of stress similitude, iron blocks were added to the test model (see Fig.2).

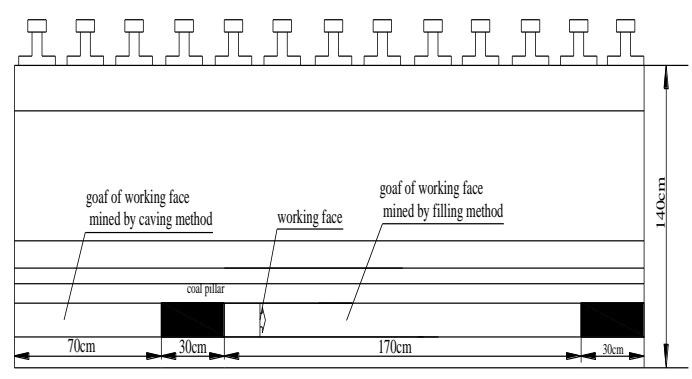

Fig. 2: Physical model of backfill mining

\section{Filling and mining process}

\subsection{Filling equipment}

Filling equipment consists of three parts: grouting device, compression system and filling groove. Compression system is realized through jack. The upper part of grouting device is made of low carbon steel, it is supported by a round base that is made of iron plate, and both sides of base is made of U-shape steel. Filling groove is made of transparent polyethylene board, its size is $40 \mathrm{~cm} \times 3$ $\mathrm{cm} \times 3 \mathrm{~cm}$.

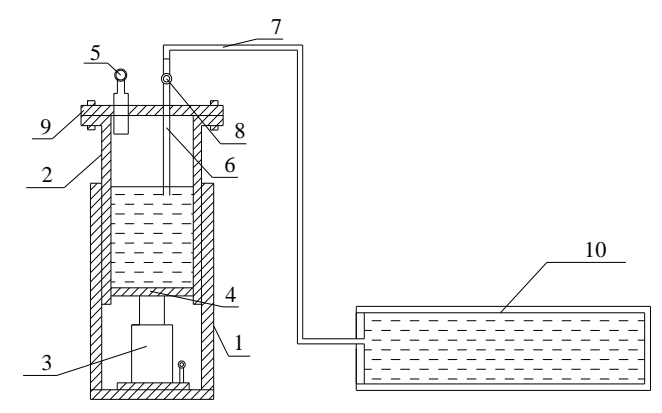

1-base; 2-inner cylinder; 3-jack; 4bearing plate; 5 - pressure gauge; 6 - pumping port; 7-high-pressure hose; 8 -flowmeter; 9 - head cover; 10 - filling groove

Fig. 3: Work principle diagram of indoor paste filling

\subsection{Optimization of filling similar materials}

Preparation of filling similar materials is the experimental basis. Filling similar materials consisted of cement, river sands and fly ash, its strength, plasticity and fluidity were tested in experiment. Similar material mixture (cement : fly ash : river sands equals $1: 7: 31$ )that can completely simulate stress-strain feature and hydration process of filling materials of Daizhuang Coal Mine were obtained.

\subsection{Filling and mining process}

The first step of fill mining is mining coal. mining step is 3 centimeters and filling step also is 3 centimeters. the second step is filling slurry preparation. Filling slurry was prepared according to the front 
mixture, and then loaded them in filling pump. The third step is filling goaf.

\section{Test results analysis}

\subsection{Distortion and failure character of overburden by filling}

Cracks are formed in the strata of $\mathrm{R} 1$ and R2, but the Cracks don't develop, when the backfill mining face promotes to 21 meters. Abscission layer occurs in the strata of R1 and R2, and produce penetrative fractures when the backfill mining face promotes to 34 meters.

Because of incompatibility of strata's combinatorial movement, the mudstone above working face falls rapidly. Abscission layer between mudstone and upper strata develop rapidly, the range of abscission layer is 25 meters and its maximum height is 10 centimeters. With the continuously mining of working face, abscission layer developed upwards gradually, the final development height is 26 meters. There is no obvious cracks in the strata above the coal wall of filling area's both side. rock deformation is mainly bend ( see fig 4). Test results are in general agreement with the field measured results of paper 5 .

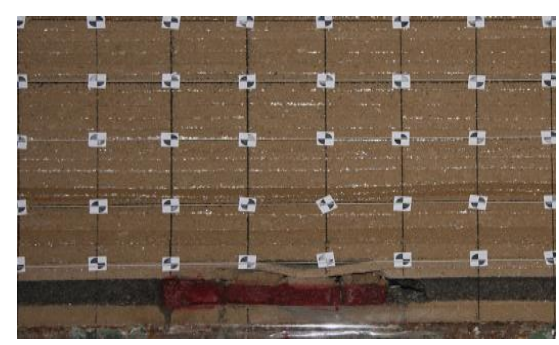

(a) Working face advancing $34 \mathrm{~m}$

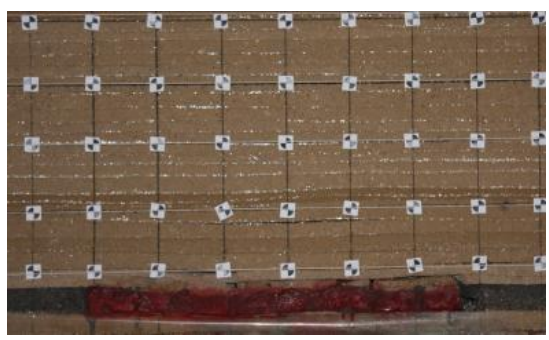

(b) Working face advancing $60 \mathrm{~m}$

Fig.4:Overlying strata movement and deformation during mining strip pillar with gangue paste

The left coal seam of the model are mined by caving method, R1, R2 strata caving gradually accompanied with workface. Many criss-crossing and irregular separations and fractures appear in overburden stratum. The development height reaches to 68 meters for the overburden fractures and separations. Fractured zone develops obviously on one side of coal wall, and forms a semi-arched structure at last.

Compared fill mining and caving mining, it is well known that the timely filling goaf can reduce the free activities space of the roof stratum. The support of filling body to the roof reduces the damage extent of the lower roof, the movement overburden stratum is effectively controlled. Therefore, it is the key to controlling the movement deformation of the lower roof is the key to overburden control of fill mining. 


\subsection{Action mechanism of filling body and overburden strata during mining strip pillar backfill with gangue paste}

The overburden strata is supported by coal pillar and coal wall in the early days of fill mining. Compressive strength of filling body is lower and there is little support function. After the initial fracture of R1 and R2 strata, form a approximate cantilever structure that there was elastic support at the cantilevered end. The roof was supported by the structure of "coal pillar-filling body-coal wall".

Filling body will behavior deformation slowly under pressure due to R1, R2 strata have the filling support after cracking. When the sinkage of $\mathrm{R} 1, \mathrm{R} 2$ strata cantilever reaches to the limitation, it will crack in the front of coal wall. Therefore, the periodic fracture of R1, R2 strata is gentle.

\section{Conclusions}

(1) Similar material simulation test showed that R1 and R2 strata would break periodically after the initial fracture, and its initial fracture length id $34 \mathrm{~m}$.

(2) Setting a certain width of pillar was very important, when strip pillar was mined with gangue paste. Filling body had little strength in the early days of fill mining. The overburden strata was supported by coal pillar and coal wall, which gained time for enhancing the strength of filling body. The roof structure of "coal pillar-filling body-coal wall" can control mining subsidence effectively.

\section{Acknowledgements}

This work was financially supported by National Natural Science Foundation of China(51274132,U1361105); Specialized Research Fund for the Doctoral Program of Higher Education(20133718110001)

\section{References:}

[1] LIU Jinxiao, "Study of paste filling material and overlying strata subsidence control in laboratory," Qingdao:Shandong University of Science and Technology, pp.34-42,2009.

[2] YANG Weifeng, XIA Xiaohong, LIU Wangwei,"Analysis of effect of coal pillars for strip extraction on surface buildings," Mining Safety \& EnvironmentalProtection, 2005.

[3] GUO Weijia,"Analytic method of overburden subsidence bed separation,"Journal of China Coal Society, pp. 49-53,2000.

[4] LI Xingshang,"Study on mechanism of the grouting backfill in caving area with strip mining under buildings,"China university of mining and technology, 2008 
[5] CHEN Shaojie, GUO Wei-jia, ZHOU Hui,"Structure model and movement law of overburden during strip pillar mining backfill with cream-body," Journal of China Coal Society, pp. 1081-1086,2011. 